\title{
A MÁQUINA TEÓRICA: 0 DISCURSO DE CHRISTOPHER NORRIS SOBRE O PÓS-MODERNISMO NA DÉCADA DE NOVENTA
}

REEEREANCIAS BIBLLOGRÉFICAS

AHMAD, Aijoz. "Culture, Notionolism, ond the Role of Intellectuals: An interview with Aijoz Ahomod". Monthly Review (jullyAugust), 41.70 .

AHMAD, Aijoz. 1992. In Theory. London: Verso.

ALDRIDGE, Owen. 1960. Comporofive Literoture: Motter ond Method. urbono: U. of Illinais Press.

BASSNEET, Suson. 1993. Comporotive Literofure: A Critical Introduction. Oxford: Blockwel.

BENJAMIM, Wolter. 1969. Illuminotions. New York: Schocken

Come Johns Hopins Ui apolize?

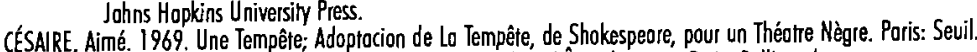

FOUCAULT, Michel. 1961. Folie et Déroison: Histoire de lo Folie ò l'Áge Clossique. Poris: Gollimord.

FOUCAll, Michel. 1976 "Ouestions of Geogroph" In: Power and Knowled ge, ed. Colin Gordon. Brighton.

FuCaut, Michel.

JAMESON Fredric 1980 "Monism ond Teoching". In: New Politicol Science 1, 2/3 (Foll-Winter), 31-36.

JAMESON, Fredric 1981. The Polititiol Unconscious. New York: Ithoco.

JAMESON, Fedric 1984. "Postmoodernism, or the Cultural Logic of Lote Copitolism". In: New Left Review, 146, 53-92.

JAMESON, Fredric 1986. "Third-World literonture in the Ero of Multinotiono Copitolism". In: Social Text, 15.

JAMESON", Fredric 19870. "A Brief Response". In: Sociol Text, 17.

JAMESON, Fredric. 198\%b. "The State of the Subject". In: Criticol Quorterly 29.4 (Winter), 16-25.

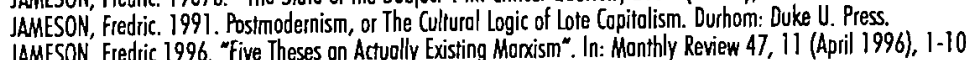

JAMESON, Fredric 1996. "Five Theses on Actuolly Existing Moxism". In: Monthly Re

MACHEREY, Pierre. 1966. A Theory of liferory Production. Londan: Routledge, 1978.

RETAMAR, Roberto Fernondes.

Minnesotto Press.
SAID, Edword. 19780. "The Problem of Textuality: Two Exemplor

SAID, Edword. 19780. "The Problem of Textualin: Iwo Exemp

SALD, Edword. 19786. Orientolism, London: Chotto \& Windus.

WALLERSTEN, Immonuel. 1974. The Modern World. System. 2 vols. New York: Academic press.

WEBER Somuel. 1983. "Copitolizing History: Notes on The Polificol Unconscious". In: The Politics of Theory, eds. Froncis Barker el

olii. Colchester: U. of Essex Press.

Young, Robert. 1990. White Mythologies: Writing History ond the West. London: Routledge.
Adam Sharman

Universidade de Nottingham

RESUMO:

O presente ensaio oferece uma exegese crítica dos sete livros que, até o final de 1997, o teórico e crítico britânico Christopher Norman dedicou ao pós-modernismo, considerando-se que a temática de Norris é a teoria pósmodernista, não os artefatos culturais ou processos pósmodernistas pelos quais ele demonstra pouco interesse. Nessa trajetória, são entrelaçados os fios de diversas questões: o entendimento de Norris do pós-modernismo; as objeçôes que ele faz à teoria pós-modernista; o teor de sua discordância de pensadores como Baudrillard com relação à Guerra do Golfo; a nota de desalento que pauta sua visão do pós-modernismo; o impacto do contexto político de direita de Margaret Thatcher sobre sua visão pessimista dos intelectuais pós-modernistas no início da década. Sobretudo, o ensaio rastreia a crítica reiterada de Norris à excessiva extensão conferida à lingüística saussureana, na sua opinião, a raiz de um mal-elaborado "relativismo cultural", bem como seu amplo comentário sobre o afastamento de Michel Foucault do pensamento de Kant. Norris crê que esse encontro ilustra, de forma exemplar, o afastamento pós- 
modernista dos valores iluministas de verdade, crítica e razão universal, cujo corolário, para ele, é a eliminação de qualquer vinculação, baseada em princípios, entre a prática intelectual e o domínio ético-politico. O ensaio oferece, paralelamente, um número de críticas a Norris (inclusive seu hábito de processar diversas posições numa máquina teórica abstrata e imperdoável), ao ressaltar as muitas alternativas à teoria pós-modernista que ele explora (filosofias pós-analíticas do significado, filosofia da ciência, realismo causal, a desconstrução de Derrida e de Man). $O$ ensaio conclui estabelecendo uma distinção entre relatividade e relativismo e enfatizando que também a epistemologia necessita de uma ética e de uma responsabilidade - com relação aos textos, pensadores e contextos -, não PALAVRAS-CHAVE: seccionáveis do tecido do pós-modernismo.

Teoria pós-modernista, mal-estar da cultura, teoria crítica, Iluminismo, ética, Relatividade, Relativismo.

Os livros de Norris foram escritos para serem lidos no ritmo de um por ano, num espaço de sete anos; somente a um analista cabe a tarefa de ler sete livros com apenas um pouquinho mais de tempo do que o Senhor levou para criar o universo e usufruir de um dia de descanso. ${ }^{1}$ Seus livros são o produto de um senso de perplexidade face ao terrível distanciamento, sofrido pela teoria crítica, da busca da crítica ético-epistemológica baseada em princípios (o que ele diz de Alex Callinicos, "se sentindo sozinho como Abdiel", pode se aplicar a ele próprio). ${ }^{2}$ Os livros emanam de uma obsessão que se harmoniza com a própria obsessão com que a teoria pós-modernista ${ }^{3}$ retrabalha seus temas prediletos, ou, talvez, sejam produzidos por essa obsessão.

1. Os livros anolisodos sōo os seguintes: What's wrong with postmodemism: criticol theory and the ends of phillosophy (New York: Harvester Wheotsheof, 1990); Spinozo ond the origins of moden criticol theory (Oxxford: Bosil Blockwell, 1991); Uncritical theory: postmodemism, intellectuals and the Gulf War (London: Lowrence ond Wishort, 1992); The truth obout postmodemism (Oxford: Basil Blockwell, 1993); Futh ond the ethics of criticism (Monchester: Monchester University Press, 1994); Recloiming fruth: contribution to o critique of cultural relativism (London: Lawrence ond Wishort, 1996); New idols of the cove: on the limits of ontiredism

eus agrodecimentos o Jon Simons por suas sugestōes e críticas, sobretudo com reloşāo às questöes mais amplas do pós-madernismo. 2. NORRIS, 1996:181.

3. NOTA DO TRADUTOR: o uso intencional do expressōo "pós-modernista" no texto original, pora ossinalar o distrinşoo de um estado "pós-moderna", é mantida na troduşo.
A especificidade cronológica dos anos noventa, a que meu título se refere, obviamente não pode ser considerada como uma ruptura epistemológica na obra de Christopher Norris, ou mesmo sugerir que ele nunca havia refletido sobre o pós-modernismo antes do primeiro minuto do dia primeiro de $1^{\circ}$ de 1990. Pelo contrário, há uma profunda continuidade no pensamento de Norris. Em The contest of faculties (1985), em Deconstruction and the interests of theory (1988) e em outras obras, já existe uma preocupação e apreensões com relação ao que se chama pós-modernismo. Ademais, no seu primeiro livro explicitamente sobre o pós-modernismo, What is wrong with postmodernism, publicado em 1990, Norris informa ao leitor que a Introdução foi escrita no último dia de 1989. Essa questão, como veremos, não é irrelevante.

\section{A teoria pós-modernista como um mal-estar cultural}

A objeção que Norris faz ao pós-modernismo é, em grande e igual escala, modelada pelos contextos político e intelectual dos anos noventa, "os desalentos da política atual britânica e americana", como ele escreveu naquela época. ${ }^{4} \mathrm{O}$ próprio Norris chama a atenção para esse contexto, que é sobretudo, mas não exclusivamente, britânico. What's wrong with postmodernism esboçase na contra-revolução de Margaret Thatcher e nas recaídas em série, por ela precipitadas, da política do Partido Trabalhista. Em meio à guinada política para a direita, o surgimento da atividade teórica nas Artes e nas Ciências Humanas (num país notório, com justiça, por sua descrença na teorização especulativa) pode ser vista, Norris crê (na trilha de Perry Anderson), como a resposta típica "de qualquer facção marginalizada de intelectuais dissidentes, excluídos da corrente principal da vida política e desprovidos de escolhas, a não ser cultivar uma gama de visões alternativas mais ou menos esperançosas". ${ }^{5}$ Constitui, mais precisamente, um dos seus argumentos principais a lamentável resposta do intelectual pós-modernista a essa mesma situação política. Assim, no título do seu livro sobre os intelectuais e a Guerra do Golfo, a teoria crítica se torna uma Uncritical theory, ${ }^{6}$ um estado de coisas que gera em Norris não

\section{NORRIS, $1993: 14$}

5. NORRIS, 1990: 1

6. NOTA DO TRADUTOR: $O$ outor cito, no decorrer do ensaio, inúmeras abras de Norris em inglês e outras, sobretudo de pensadores

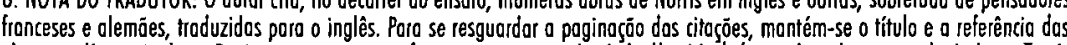
obras em linguo ingleso. Registra-se oqui, especificamente, a ironia do fiftula Uncititical theary, literalmente traduzivel por leorio acifica. 
apenas desdém (com relação a Jean Baudrillard e congêneres), mas também tristeza e, às vezes, desespero. Os quatro primeiros livros desse período, em particular, são marcados por expressões de pessimismo.

A obra de Norris, contudo, é também um grito de incitamento à luta, e seus ensaios têm consequiências que transbordam as fronteiras da teoria crítica e cultural:

De fato, eles se situam no âmbito da única e mais premente questão confrontada pelos pensadores de esquerda na Grã-Bretanha e nos Estados Unidos, ou seja, o que resta do projeto socialista numa época em que valores consensualmente distorcidos chegaram ao ponto de definir a agenda do debate político "informado" ou "realista".?

Norris é um ser ostensivamente político, interessado na relevância desses temas "fora e além dos enclaves especializados da teoria crítica e cultural". ${ }^{8}$ Há uma definição melhor, mais sucinta, de um "teórico" dos nossos dias?

Há - o que é mais relevante para os nossos propósitos - uma definição sucinta do que Norris entende por pós-modernismo?

Numa passagem de Uncritical theory, Norris lembra-nos que o pósmodernismo, enquanto fenômeno cultural, deve ser distinguido do pósmodernismo enquanto teoria. Deve-se enfatizar bastante que é o pós-modernismo enquanto teoria que ocupa a atenção de Norris, e que ele e o Fredric Jameson de Postmodernism ou The cultural logic of late capitalism discorrem sobre um fenômeno totalmente diferente. Ocasionalmente, Norris menciona, digamos, um romance pós-moderno, ou admite a pertinência do que um Baudrillard tem a dizer sobre a "hiper-realidade" da política de hoje. Mas na raiz de sua preocupação está a teoria, um tipo de produção teórica que, com frequiência, tomando como o seu objeto de estudo uma era ou uma problemática totalmente distanciada da pós-modernidade, manifesta certas facetas inquestionáveis e, para o próprio Norris, perturbadoras. Menciono, por exemplo, um relativismo total, um ethos anti-iluminista, um desvio das noções tradicionais de crítica baseada em princípios, uma lealdade inabalável à "virada lingüística" e idéias correlatas sobre a construção discursiva da realidade.
O seu assunto, então, é a teoria. E os teóricos: Lyotard, Baudrillard, Hebdige, Jameson... A lista de nomes é muito mais longa pela simples razão de que, como indicam alguns dos títulos dos seus livros, a abrangência de Norris ultrapassa os campeões óbvios do pós-modernismo para abarcar aqueles que, sejam eles "neo-pragmáticos", "relativistas ontológicos" ou adeptos da "Nova História" compartilham, no seu entendimento, as mesmas premissas e, por extensão, a mesma "confusão moral" induzida pela "virada linguíística". 9 Para testemunhar: Rorty, Fish, Foucault, Greenblatt, Geertz, os pós-estruturalistas, teóricos literários não mencionados. Há na academia ocidental uma "doença cultural disseminada para a qual 'o pós-modernismo' é um termo útil de diagnóstico". 10

Sete livros sobre a teoria pós-modernista, relativista ou anti-realista - a produção de Norris é surpreendente (não são esses os únicos livros que ele publicou no período); sua considerável gama de interesses inclui uma admiração por William Empson do tipo "não-consigo-tirá-lo-do meu sistema", e a quem ele dedica ensaios periodicamente, bem como um caso antigo com a música, que constitui não só o assunto de livros recentes, mas também, na realidade, seu ponto de partida acadêmico. Todavia não se pode evitar uma sensação de que a categoria excluída, ou seja, o "pós-modernismo como um fenômeno cultural" poderia ter sido objeto de atenção, de forma que o "objeto" falasse ou replicasse (uma das principais posições de Norris é que a teoria pós-modernista ou correlata simplesmente não respeita e, na realidade, tenta considerar como inexistente aquilo que pensadores antiquados chamariam de "coisas").

De qualquer forma, podemos explicitar, em termos gerais, a razão da objeção de Norris à teoria pós-modernista tomando suas próprias palavras em Spinoza and the origins of modern critical theory. Este livro, o mais coeso e convincente dos sete, pelo fato de que os argumentos, às vezes divergentes, têm a figura de Spinoza como o centro de gravidade, volta-se para o metafísico do século XVI para ressaltar o recente renascer do interesse em tais filosofemas por pensadores "como Foucault, Deleuze e Lyotard", ansiosos "em revogar o paradigma do 'Iluminismo' kantiano, argumentando que 'o homem', ou o sujeito transcendental, na realidade não era mais do que um episódio transitório na ordem dos regimes discursivos mutáveis, uma 'dobra' no tecido do conhecimento e representação cuja hegemonia já estava chegando ao fim”.
7. NORRIS, 1993: 28.

8. NORRIS, 1993: 28
9. NORRIS, 1993: 20.

10. NORRIS, 1992:16. 
Norris prossegue:

Por essa razão, a idéia de que os argumentos de verdade poderiam sempre ser legitimados — ou, em última instância, excluídos do júri - se levados para o tribunal crítico das faculdades era meramente um sinal do prestígio outrora gozado por essa entidade fantasmagórica e ilusória. [...] Seus argumentos foram desfeitos, dentre outras coisas, pelo "descentramento" freudiano da subjetividade racional autopossuída; pela revolução estrutural na lingüística por Saussure (onde o pensamento se torna, analogamente, um sistema puramente diferencial "sem termos positivos") e pelo ataque de Nietzsche a todos os sistemas de conhecimento e valor que mascaram seu desejo-de-poder por detrás de uma retórica de verdade pura e desinteressada. Há, no mínimo, certas questões que não são respondidas por esse abandono por atacado da razão crítica em nome de um novo regime (pós-moderno) desprovido de garantias transcendentais. ${ }^{11}$

A palavra "pós-moderno" e seus cognatos migram da posição parentética, como na citação acima, para um lugar privilegiado nos títulos de livros completos.

Além da razão supracitada, Spinoza reveste-se de interesse para Norris por duas outras razões; primeiramente, por ter sido Spinoza o primeiro a praticar uma exegese textual calcada na leitura de obras canônicas que ele tratava não como fontes de verdade revelada, mas como documentos na história de instituições civis e políticas em mutação; em segundo lugar, em decorrência da importância que ele conferia aos valores epistemológicos $e$ ético-políticos. Para Norris, o recrutamento de Spinoza para a tarefa de ataque filosófico ao Iluminismo e uma leitura altamente seletiva praticada pelos pelotões de recrutamento pós-modernistas (apropriando-se da metafísica de Spinoza, mas ignorando o eixo que conecta o epistemológico ao ético-político) são sintomáticos das confusões, para não mencionar o oportunismo, que assolaram o pensamento pós-modernista. Uma teoria crítica igualmente enganada pelo pós-modernismo sente-se inapta a assumir uma postura de oposição baseada em princípios, um aspecto cruelmente exposto na resposta dos intelectuais à Guerra do Golfo.

11. NORRIS, 1991: 33-34.

\section{Baudrillard e a Guerra do Golfo}

Sob a ótica de Norris, a cumplicidade entre a doutrina anti-realista e a crise de coragem moral e política encontra sua voz mais irrefletida na análise feita da Guerra do Golfo por Baudrillard, "The reality gulf". Para Baudrillard, escrevendo pouco antes da eclosão da guerra, ela nunca aconteceria, existindo como o foi, segunda a leitura de Norris, "apenas como uma invenção da simulação da mídia, da retórica dos jogos de guerra ou de cenários imaginários que excediam a todos os limites do mundo real e da possibilidade factual". ${ }^{12}$ Mesmo se a guerra acontecesse, todas as pessoas - de presidentes a espectadores dos horários nobres, de correspondentes internacionais aos chamados generais de "linha de frente" - teriam de se basear num conhecimento em segunda mão ou simulado dos acontecimentos. Ninguém saberia, com certeza, se a informação não era "um 'simulacro' fictício do real, conjurado pela máquina-de-propaganda ubíqua ou pelas várias técnicas de desinformação da mídia". "De fato", Norris continua com seu sumário do caso Baudrillard:

é culposamente ingênuo continuar a pensar nesses termos, como se permanecesse alguma diferença operante entre a verdade $e$ a falsidade, $o$ conhecimento verídico e sua semelhança na forma criada pelos mecanismos de retroalimentação nos informes da mídia, nas pesquisas de opinião, nos "debates parlamentares", etc. É porque tais efeitos são tão "reais" quanto capazes de influenciar o curso diário dos acontecimentos - como qualquer coisa que possa (por tudo que podemos saber) de fato ter acontecido ou estar acontecendo agora, além do alcance da saturação da cobertura televisiva. Em síntese, não se chega a lugar nenhum lamentando a ausência de informação factual, objetiva ou sem preconceito, quando simplesmente não possuímos uma régua —algum parâmetro para a comparação - que permitiria, mesmo ao observador mais especializado, alcançar uma perspectiva crítica. "Nosso lugar estratégico é a tela da televisão, a partir da qual somos diariamente bombardeados". ${ }^{13}$

A Guerra do Golfo é apenas o exemplo mais espetacular da "hiper-
12. NORRIS, 1992: 11 .

13. NORRIS, 1992: 12 
realidade" na qual nos encontramos atualmente. Qualquer crença numa realidade além das aparências deve estar ciente de que as aparências são tudo que possuímos. Tomo a liberdade de citar na íntegra uma passagem de Norris na qual ele se afasta das especificidades do artigo de Baudrillard para uma afirmação da filosofia geral desse pensador francês. Ela sintetiza bem a tendência geral da teoria pós-modernista:

Durante um longo tempo - mais de dois milênios — prevaleceu a idéia, entre filósofos, moralistas, teóricos sociais e outros, de que se poderia de fato chegar à verdade através de um esforço de pensamento crítico baseado em princípios, um processo que finalmente permitiria ao pensador discernir proposições verídicas (ou valores autênticos) de várias modalidades de ilusão, falsa consciência, percepção ideológica distorcida, etc. Desde Platão até Kant, Hegel, Marx e outros, essa conviç̧ão manteve-se firmemente, apesar das múltiplas mudanças paradigmáticas que caracterizaram a história do pensamento ocidental. Mas agora ela se tornou obsoleta, na opinião de Baudrillard, na medida em que perdemos todo o nosso senso de diferença - a diferença ontológica ou epistemológica - entre a verdade e as várias imagens semelhantes à verdade, análogos e substitutos da fantasia que atualmente reclamam esse título. ${ }^{14}$

A crítica que Norris faz a Baudrillard, que se encontra, de fato, no livro anterior, What's wrong with postmodernism, resume-se numa análise notável da confusão fundamental no trabalho desse pensador entre uma questão ontológica ("o que aconteceu") e uma epistemológica ("que dificuldades enfrentamos ao conhecer o que aconteceu?"). ${ }^{15} \mathrm{O}$ argumento é bem estruturado. Suspeita-se, também, no caso de Baudrillard, que, em nome de uma dúbia pretensão demótica, haja um privilegiar fatal do espectador da televisão como o sujeito modelo que faz indagações. "Nosso lugar estratégico é a tela da televisão, a partir da qual somos diariamente bombardeados". O soldado "aliado" no solo, o cidadão iraquiano, o jornalista inquiridor, ou o historiador paciente podem ter um "lugar estratégico" totalmente diferente, no qual a dicotomia realidade/aparência não é uma distinção operante tão inútil. Norris também, com rapidez, aponta o "truque performativo" de Baudrillard, que consiste em jogar com as distinções como verdadeiro/falso, realidade/aparência, enquanto,

14. NORRIS, 1992:15

15. NORRIS, 1992: 122 em termos retóricos, faz com que elas desapareçam. ${ }^{16}$ Nos termos mais banais, nada sobre o que Baudrillard discorre na sua frase "a perversão da verdade e da falsidade" da mídia poderia começar a fazer sentido sem um entendimento operante bem firme da distinção da categoria verdadeiro/falso.

É esse senso de se fazer época através da subversão do pensamento ocidental que, creio, estimula os leitores de Baudrillard. No cenário, nada de Platão, nada de Kant; nós habitamos o nosso mundo, um mundo de sofisticação material e tecnológica com o qual não sonhavam nossos antepassados e nós construímos o nosso próprio sistema lógico-semântico para pensar sobre esse mundo. O que tamanha presunção e ignorância desconhecem, como reitera Norris muitas vezes no decorrer de todos os seus livros, são os vários encontros ao longo dos séculos em que tais questões epistemológicas foram ensaiadas. Ele não se esquiva de apontar a visível ignorância da história do pensamento ocidental manifestada por muitos expoentes da teoria pós-modernista. Há um firme sentido em que todos os sete livros da década de noventa são direcionados: a um grupo de acadêmicos particularmente habituados, na percepção de Norris, a ignorar totalmente essa tradição filosófica que eles pensam criticar tão firmemente ou a exibir um conhecimento não muito acurado dela. Refiro-me, ele se refere, aos teóricos da literatura. Eles são, claramente, os principais alvos. Norris acredita que o abarcar dos princípios pós-modernistas por teóricos da literatura pode ser interpretado como um grande ato de vingança após séculos de subordinação aos cientistas e aos filósofos na hierarquia das academias, depois de todas as "humilhações magistrais a que foram submetidos, desde Platão até os positivistas lógicos". ${ }^{17}$

Há algo que permanece estranho a respeito de Uncritical theory - o fato de a análise pormenorizada da posição de Baudrillard, cujos princípios e teor constituem o ponto de partida do livro, encontrar-se em texto anterior. No livro, que ostenta o subtítulo Pós-modernismo, nunca emerge uma análise cuidadosa de Baudrillard. Em seu lugar, Norris examina as consequiências éticoepistemilógicas que emanam da epistemologia de uma série de pensadores pósmodernistas ou relativistas e, por extensão, avalia seu pensamento sobre um debate em torno da Guerra do Golfo, para o qual eles nunca contribuíram. Teria sido menos desorientador se ele tivesse anteposto ao título Ensaios sobre. Da forma como ele se apresenta, a despeito de todos os argumentos válidos trazidos para evidenciar as incoerências lógicas de várias outras manifestações de erro

16. NORRIS, 1990: 182.

17. NORRIS, 1994: 8 . 
semelhante (as de Stanley Fish, Jean-François Baudrillard, Michel Foucault), o livro padece por ter suas origens na indignação e exasperação fervorosa provocadas por um (e, sem dúvida, insensato) artigo de jornal.

\section{A síndrome da compilação e os alvos de Norris}

Uncritical theory não é o único livro a sofrer da "síndrome de compilação". Muitos dos livros são constituídos por ensaios (muitas vezes, resenhas críticas) que nem sempre se coadunam. Há também incoerências internas, a exemplo de The truth about postmodernism, no qual ele não logra entrelaçar os elementos do Capítulo 2 (sobre Foucault e Kant) ao Capítulo 5, deixando-nos uma versão de Foucault (que proclama que "nada pode ser pensado fora do alcance dos discursos ou posições dos sujeitos impostos por alguma configuração existente de poder/saber") que ele havia demonstrado antes ser apenas uma encarnação, embora dominante. ${ }^{18}$ Em outros momentos, atropela-se na tentativa de reunir os vários fios da argumentação através de um tema comum. O primeiro capítulo de Reclaiming truth propõe examinar as várias aplicações crítico-teóricas da palavra e do conceito "discurso", mas falha abertamente em mantê-lo sob exame. O livro mais problemático nesse sentido é o primeiro da série de 1990. What's wrong with postmodernism força a aproximação de ensaios variados nem sempre condizentes com o que se explicita ser o assunto do livro. Assim, o primeiro capítulo, sobre a interpretação errônea que Derrida faz de Habermas como um pós-moderno, não se coaduna bem com a Introdução, embora ele se salve um pouco na parte sobre a crítica que Derrida faz da Histoire de la folie de Foucault. O capítulo 3, "Limited think: how not to read Derrida", novamente se mostra como um ensaio situado de forma estranha. Ele não guarda relação com o pósmodernismo, exceto na censura feita a esses críticos que lêem em Derrida um adepto dessa causa. O capítulo 5, "Derrida and Kant", é simplesmente uma resenha, embora muito boa, do livro de Irene Harvey, Derrida and the economy of "différance", e não guarda relação com o pós-modernismo. Finalmente, o último capítulo, "Settling accounts: Heidegger, de Man and the ends of philosophy", analogamente, não se relaciona com o pós-modernismo (trata-se de uma resenha do livro de Lacoue-Labarthe, Heidegger, arte e política), ainda que as reflexões de Norris sobre Paul de Man constituam evidência de seu (digo, de Norris) tema em relação a esse movimento. ${ }^{19}$

18. NORRIS, 1993: 293.

19. Vide NORRIS, 1990: 276 .
Há, também, deve-se dizer, excessivas repetições internas e no conjunto dos livros. Em primeiro lugar, ao nível da semântica e da fraseologia (algumas das expressões são chavões de outros de quem Norris discorda): "ultrarelativismo da moda", a textualidade ou a retórica seguem "sem base de apoio que assegure o significado", etc. Há também o nível argumentativo e temático". Em Truth and the ethics of criticism, Norris retorna repetidamente ao livro de Foucault sobre a loucura e à crítica a ele feita por Derrida, um debate que, como disse, já havia sido bem trabalhado em What's wrong with postmodernism, respaldando a mesma crítica de Stanley Fish. Rorty reaparece outras vezes e The differend: phrases in dispute de Lyotard é revisitado em inúmeras ocasiões.

Com relação a Fish, Rorty e Lyotard, em cada caso, para Norris, há um entendimento inadequado da relação entre teoria (ou linguagem) e verdade. Fish crê que a teoria pode ter força retórica, mas certamente não tem valor de verdade. Rorty crê que toda a filosofia é meramente uma questão de conceitos e metáforas que se rivalizam, sendo que nenhuma delas é naturalmente mais adequada ao mundo do que a outra. Lyotard é objeto de atenção especial. Em capítulo marcante de Uncritical theory, "Do sublime ao absurdo (Lyotard)", Norris sintetiza a posição de Lyotard: o conhecimento é uma questão de "regimes frasais" radicalmente heterogêneos, sendo que nenhum deles pode impor sua própria reivindicação de verdade sobre os outros sem, assim, reduzir, pela sanção do autoritarismo, a incomensurabilidade essencial, o "diferendo", entre eles. Não há princípio de justiça mais importante do que a manutenção de uma pluralidade de "jogos de linguagem", uma posição que explica o recurso feito por Lyotard do "sublime" de Kant como o que excede todas aquelas formas de conhecimento conceitual, etc., "que normalmente norteiam nossa idéia do que se conta como uma contribuição válida para o debate". ${ }^{20}$

\section{O Iuminismo}

Para Norris, em contraste, a oposição aos valores esposados por Kant, Diderot, Rousseau e outros apenas pode começar a exercer uma influência convincente em virtude de uma visão excessivamente monilítica do Iluminismo: como geradora de uma doutrina rigidamente prescriptiva e autoritária que, quando aplicada ao maquinário da sociedade, só pode levar à tirania. Essa visão caricaturesca obscurece a visível variedade dos projetos Iluministas e o ethos

$$
\text { 20. NORRIS, } 1992: 79 .
$$


crítico em cuja base os pensadores Iluministas trabalharam incessantemente para questionar e desafiar seus próprios hábitos de crença e pressupostos. ${ }^{21}$ Truth and the ethics of criticism, um dos mais definidos e, consequientemente, coeso e eficaz dos livros, elabora bem esse argumento, cotejando o teor "preconceituoso" das palavras de Lyotard sobre as "metanarrativas" e "discursos mestres" com o relato pormenorizado e matizado de Peter Gay nos dois volumes do seu The Enlightenment: an interpretation:

Nunca houve um movimento de pensamento mais fendido, internamente fraturado e discutível do que a empresa lançada pelos philosophes franceses e elevada a um ponto mais alto de reflexão crítica por Kant e pensadores subseqüentes. De fato, não foi apenas um traço do período mas uma característica definidora do Projeto Iluminista, engajado como era - e como Kant mais explicitamente proclamava - a um princípio de liberdade no questionamento de idéias e valores recebidos. ${ }^{22}$

Como, Norris pergunta, pode o pós-estruturalismo ter a pretensão de tocar nas políticas materiais e instituições se ele rejeita os valores de verdade e crítica cultuados na filosofia do Iluminismo, se ele mantém a linha relativista de que tudo é construído no discurso? Por que deve qualquer instância de discurso (clamando por justiça para um homem preso por engano ou pela igualdade de oportunidade para as mulheres, ou pela crença de que o Holocausto ocorreu) ter uma pretensão maior de verdade do que qualquer outra (que se opunha a todos os casos acima)? Não se trata, necessariamente, de dizer que os proponentes do pósmodernismo e do pós-estruturalismo são destituídos de consciência ética; o fato é que seu trabalho teórico não oferece critérios para decisões éticas, ainda que o trabalho seja ancorado, a todo momento (como no caso de Foucault), por certos pressupostos éticos implícitos. Novamente, Truth and the ethics of criticism se revela eloquiente nesse aspecto. Proclamar o fim das "grandes narrativas", a morte do "significado transcendental" e da Verdade unitária tacitamente significa aceitar estas distinções (verdade/falsidade, razão/retórica, interesses humanos reais/ representação ideológica distorcida) que representam o maior legado do Iluminismo. "Tais projetos não teriam nenhum significado ou finalidade (seriam de fato ininteligíveis) se não fosse pelo seu engajamento tacitamente reconhecido aos mesmos princípios e valores". ${ }^{23}$ É isso que Habermas denomina "contradição

21. NORRIS, 1993: 286.

22. NORRIS, 1994: 31 .

23. NORRIS, 1994: 33. performativa" no cerne de todos os ataques frontais ao discurso filosófico da performativa" no cerne de todos os a fontes conceituais de empréstimo à tradição que eles desejam desmantelar. Norris acrescenta um outro argumento instigante (também colocado por Peter Dews em Logics of disintegration), ou seja, há no "ultra-relativismo" de um Lyotard um erro fundamental que consiste em suprimir "ultra-relativismo" de um presumível à Verdade da forma como ela é revelada a algum grupo autorizado presumível a do debate argumentativo aberto". Vale a pena continuar a citação de Norris, do debate argumentativo aberto". Vale a pena continuar a citação de Nom celaça ao credo fossilizado em que se transformou um certo tipo de pós-modernismo. Todavia eu preferiria atenuar a expressão "nada poderia ser mais" por "em razão de uma ironia curiosa, nada poderia ser mais dogmático - menos desejoso de engajar em debates deste tipo - do que a nova ortodoxia ultra-relativista que permite aos opositores a escolha não invejável de figurar ou como ingênuos ou como inquisidores, vítimas ou agentes desse desejo de poder que se mascara como razão crítica."24

\section{Foucault e o legado kantiano}

Nesse ponto, tendo feito ressurgir o espectro do "desejo de poder" de Nietzsche, gostaria de examinar com maior profundidade o ensaio de Norris sobre Foucault e Kant, um trecho longo de um livro, The truth about postmodernism, dedicado a um número mais reduzido de meditações mais fundamentadas.

Na Introdução ao livro anterior, What's wrong with postmodernism, os alvos principais das investidas de Norris são Lyotard e Baudrillard; não há menções a Foucault. No entanto Foucault passa a ocupar o centro do palco em The truth about postmodernism, ainda que o seja de forma vicária, porque o interesse de Norris no pensador francês reside, de fato, no engajamento de Foucault com Kant'no ensaio intitulado "What is Enlightenment?". Dando continuidade ao resgate de Kant, que já é 6́bvio, por exemplo, no segundo dos seus dois pequenos guias introdutórios a Derrida, tudo o que Norris escreve sobre a temática do pós-modernismo, anti-realismo e relativismo cultural é marcado por um senso da importância do legado kantiano (todos os cinco ensaios reunidos em The truth about postmodernism levam esse selo). Apesar de

$$
\text { 24. NORRIS, 1994: 289-290. }
$$


Foucault, de forma alguma, necessariamente se identificar com o pósmodernismo (o próprio Norris opina que "ele claramente [...] se situa distante das frivolidades auto-absorventes da moda pós-modernista atual"25). Norris considera que seguir-se o "curso sempre complexo e tortuoso dos encontros de Foucault com Kant é "a melhor forma de assimilar o que está em discussão na virada pós-modernista atual contra o discurso dos valores e das crenças do Iluminismo". ${ }^{26}$

Foucault não esperou até Les mots et les choses para se engajar com Kant. A segunda parte de sua tese de doutoramento constitui uma tradução por ele completada de Kant, Anthropology from a pragmatic point of view. Mas o que é interessante com relação a esse bem conhecido livro é que, apesar de ele relegar o pensamento kantiano a um período histórico cuidadosamente delimitado, ele permanece uma empreitada profundamente kantiana. $O$ conceito de episteme, que tanto deve à leitura muito específica que Heidegger faz de Kant (sobretudo encontrada em What is a thing?), funciona como um a priori, como uma assimilação anterior do que deveria ser uniformemente determinante de cada corpo numa época histórica específica (razão pela qual Foucault se refere ao "a priori histórico"). Apesar da aparente historicização de Kant e da polêmica que perpassa o livro em favor de uma relatividade histórica do conhecimento, Foucault formula a episteme como um conceito geral aplicável a todas as eras (mesmo que ele dê a impressão de corresponder mais fidedignamente ao conceito clássico de mathesis). Assim, o que se preserva através das configurações epistemológicas mutáveis que Foucault descreve é o caráter essencialmente axiomático do modo de questionamento e da determinação cognitiva da natureza. ${ }^{27} \mathrm{Com}$ as honrosas exceções de Norris e Ian Hacking, esta qualidade "conceitualista", nitidamente kantiana, de Les mots ainda não foi suficientemente reconhecida.

Naturalmente, questiona-se ser Discipline and punish, com sua rejeição aberta ao tema do humanitarismo progressista e a sua formulação do poder/saber influenciada por Nietzsche (embora, sob muitos aspectos nãonietzscheana), $o$ texto anti-Iluminismo. A leitura que Norris faz de Foucault é esclarecedora. Ele descreve a forma pela qual Foucault acaba encurralado num dilema clássico, que oscila entre os dois pólos de um determinismo levado a extremos — onde o sujeito nada mais é do que "uma construção transitória",

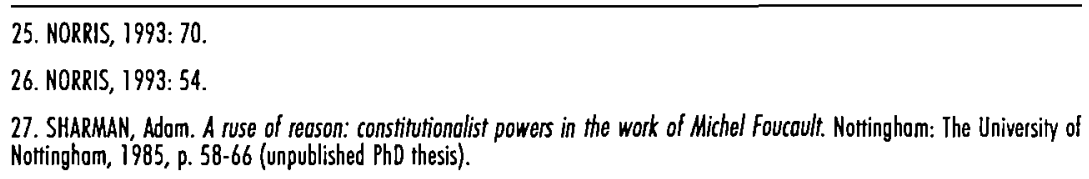

um "sujeito subjugado", conforme a colocação de Foucault em Discipline and punish - e "uma doutrina da autonomia (ou auto-invenção particular) que se resvala para uma ética e uma política anarquistas". ${ }^{28}$ Gostaria de enfatizar, ainda mais do que Norris, o fato de que esse dilema, de fato, apenas emerge após Discipline and punish. Houve, em tempos recentes, uma retratação intelectual mais dramática do que a executada por Foucault? Não se trata de dizer que Norris não apreende a "mudança"; pelo contrário, ele discerne sinais, "que estavam lá para qualquer um ler", de que Foucault, no apogeu das celebrações pós-estruturalistas da "morte do autor", da obsolescência dos valores iluministas e da construção discursiva da realidade, "fez esforços consideráveis para distanciar seu pensamento de qualquer ortodoxia totalizante". ${ }^{29}$ Eu deveria dizer, pelo contrário, que, como creio ser o caso, se Foucault fez tais esforços, o problema é que sua fuga da ortodoxia levou-o às versões mais extremas dos três alvos da crítica pós-estruturalista acima mencionados (Norris tende a citar Foucault dos primeiros tempos em meio a uma discussão dos seus últimos trabalhos, o que faz avultar um falso senso de holismo, uma diluição de distinções que não é ajudada por sua prática de omitir a paginação específica de muitas referências. ${ }^{30}$ )

Norris identifica a mudança, mas na página seguinte exagera na justificativa e não se revela acurado em um dos três pontos detalhados:

O que essa mudança representou foi um sentido crescente da falência moral e política conseqüente de qualquer projeto que efetivamente rejeitava os princípios da agência e da escolha humana. Parece ser essa a razão principal de Foucault estar agora se afastando dos três pontos principais da sua fase genealógica nietzscheana: 1) todas as alegações de verdade são inextricavelmente entrelaçadas às relações de poder/saber; 2) que o sujeito não é mais do que uma invenção do discurso, uma "dobra" transitória no tecido desse ou daquele sistema de representações; 3) que essas intravisões são suficientes para refutar qualquer argumento baseado na premissa de noções "iluminadas" de razão, autoconhecimento, interesses emancipatórios e Ideologiekritik, etc. ${ }^{31}$

28. NORRIS, 1993:51.

29. NORRIS, 1993: 31 -32

30. NORRIS, 1993:64, fn 77; NORRIS: 1993: 42, in 43 .

31. NORRIS, 1993: 32. 
"Falência", parece-me, é excessivo. Além do mais, Norris está tanto certo quanto errado com relação à questão número 1 acima. De fato, Foucault se afastou no sentido de não dar prosseguimento ao trabalho teórico sobre poder elaborado em La volonté de savoir. Ele não se afastou se, por "afastarse", nós entendemos uma rejeição explícita do postulado. Não houve tal retratação. Nem tampouco é a intravisão contida na primeira proposição incompatível com a crítica intelectual de oposição baseada em princípios e a ético-política. Que todas as alegações de verdade são inextricavelmente entrelaçadas com as relações de poder-saber (com hífen e não com barra) não é dizer - e Jacques Derrida já argumentou isso muitas vezes - que toda forma de proceder tem valor crítico igual ou de conseqüências éticas iguais.

O retour au sujet de Foucault nos volumes II e III da History of sexuality é acompanhado, como Norris afirma, por um retour à Kant. O tratamento dado por Norris a esse reencontro está entre os melhores da literatura sobre Foucault. Seu argumento subjacente é que, mesmo nessa redescoberta dos temas do pensamento do Iluminismo, Foucault mantém o impulso pósmodernista de desviar a atenção do eixo, que para Kant é crucial, entre conhecimento e ética (o peso das duas primeiras Critiques kantianas), ética e estética (a temática da Critique of judgement). Foucault pode, assim, finalmente, desmerecer os aspectos critico-iluministas do moderno em favor do ethos estético que ele encontra corporificado em Baudelaire. ${ }^{32}$ No que parece ser uma manobra surpreendente e radical, Foucault segue Baudelaire, e não Kant, ao equacionar a modernidade com a auto-invenção estética, com o espírito da transformação perpétua, com o efêmero e o contingente. Assim, ele continua a crítica do humanismo, que agora pode ser oposta "pelo princípio de uma crítica permanente e uma criação permanente de nós mesmos na nossa autonomia: isso é, um princípio que está no cerne da consciência histórica que o Iluminismo tem de si."

Norris tem plena consciência de que a palavra "critique" foi aqui reinventada, com pouco ou nenhum esforço em elaborar a tradição que lhe conferiu sua força e sem nenhuma explicação das bases epistemológicas que lhe conferem validade, ou dos valores éticos sobre os quais tal "princípio" pode operar. O resultado de sua leitura de Kant é a estetização da política, da moralidade e da justiça social, a afirmação de um "ethos particularindividualista" que tornaria obsoletos os apelos tradicionais à "razão", "à crítica" e ao "tribunal das faculdades". Foucault retorna à Grécia, ao cultivo do eu, a

\section{NORRIS, 1993:59.}

33. NORRIS, 1993: 61 . uma autoformação ascética/estética do eu, e não à posição do Iluminismo de "estratagema autopromocional, a partir da qual a razão se ergue como um árbitro derradeiro de verdade, justiça e direito". ${ }^{34}$ Para Norris, a inflexão de Foucault para o dandy de Baudelaire, para um homem que, nas palavras de Baudelaire, "se propõe a extrair da moda qualquer elemento que ela possa conter de poesia dentro da história", é o que mais aproxima Foucault do pós-modernismo.

Pois é apenas esse desejo de transformar a realidade num fenômeno estético - desfazer toda a gama de distinções ontológicas entre a vida e a arte, o fato e a ficção, a história e a poesia, a verdade e a aparência que caracteriza o impulso pos-modernista atual contra o Iluminismo e todas as suas obras. ${ }^{35}$

Norris, porém, não pára aí, com uma aceitação resignada da oposição de Foucault ao Iluminismo, pois, como ele afirma com relação a vários pensadores pós-modemistas, um aprofundamento do pensamento sobre a questão resulta na constatação de que os vários projetos de Foucault "apenas fazem sentido sob um ponto de vista crítico informado por certos valores e pressupostos distintivamente iluministas". ${ }^{36}$ Norris conclui o ensaio com um forte apelo para que se distinga Foucault da ortodoxia ultra-relativista propagada por proponentes de uma quase-universal "condição pós-moderna", argumentando que ele progressivamente se desafeiçoou do pós-estruturalismo e de movimentos aliados no cenário cultural francês. Concordo com a alegação de Norris de que há uma diferença significativa entre Lyotard e Foucault. Enquanto Lyotard é compelido, por sua epistemologia de "regimes frasais" relativizados e respeito absoluto pelo "diferendo", a se equivocar mesmo sobre a questão do "relato" revisionista de Robert Faurisson sobre o Holocausto, Foucault, ao ser questionado sobre a situação de deterioramento na Polônia em meados da década de 80 , responde, em acentuado contraste, afirmando o dever ético e político de fazer protestar "um fenômeno político que é tão substancial quanto possível”. Norris conclui:

Meu argumento é que Foucault - ao contrário de Lyotard - reconhece as exigências de certos imperativos morais, que necessariamente valem para qualquer sujeito consciencioso de posse dos fatos relevantes e cuja validade não pode ser relativizada a esse ou aquele "regime frasal",

\section{NORRIS, 1993: 62 \\ 35. NORRIS, 1993: 63 . \\ 36. NORRIS, 1993: 71 .}


"discurso" ou "forma de vida" cultural [...], pois, como Foucault descreve, a postura de "não-aceitação" é a que decorre de uma revisão crítica da melhor evidência disponível, um engajamento tornado "tão substancial quanto possível", dando-se o devido valor a todos esses fatores históricos, políticos e sócio-econômicos - que permitem que se atinja um julgamento informado. Assim, não se trata tanto de uma questão de "julgar sem critérios" (no oxímoro de Lyotard), mas de perguntar quais os critérios que se aplicam adequadamente a um conjunto específico de circunstâncias e depois decidir quais deveriam ser considerados pertinentes, de boa-fé ou uma resposta autorizada em termos éticos. ${ }^{37}$

A única coisa notável sobre esta passagem é a necessidade de se lhe colocar o argumento. As doutrinas pós-modernistas asseguraram que a necessidade está lá, e Norris é tão bom quanto os outros quando chega o momento de colocá-lo.

Discordo de Norris, por outro lado, quando ele fala aprobatoriamente da inflexão tardia de Foucault para a idéia de "problematizações", uma palavra que Foucault usa como um princípio metodológico norteador que se anuncia como distintivo de outras abordagens historiográficas. Contudo, ela pode ser melhor vista como um preconceito arquitradicional da historiografia. Em L'usage des plaisirs, Foucault tenta distinguir a história do pensamento, ou mesmo da "verdade", de uma história dos comportamentos, representações, idéias ou ideologias. "Era uma questão de analisar [...] as problematizações através das quais o ser se oferece, necessariamente, como pensamento - e as práticas sobre cujas bases as problematizações são formadas." ${ }^{38}$ Essa idéia de problematização, na minha opinião, não representa, com êxito, a mudança de posição de Foucault com relação ao "pós-estruturalismo e formas congêneres de doutrina ultrarelativista da moda". Parece-me problemático que Foucault ou qualquer outro pudesse "abandonar" o "princípio básico da doutrina pós-estruturalista - isto é, o argumento de que o pensamento é completamente constituído pelos códigos, convenções, jogos de linguagem ou discursos que configuram uma determinada ordem cultural". ${ }^{39}$ A tentativa de retirar as "problematizações" do domínio das idéias, das ideologias e, pior ainda, das representações é um esforço ingênuo de negar o processo de deciframento textual e de reconstrução histórica, sem o qual não se pode começar a identificar qualquer problematização.

37. NORRIS, 1993: 95-96.

38. FOUCAULI, Michel. L'usoge des plaisisis. Vol. 2. Histoire de lo sexualite (Paris: Editions Gollimord, 1984: 10-11).

39. NORRIS, 1993: 90-91.

\section{A máquina teórica}

O texto de Norris sobre Foucault, apesar de uma certa repetição, constitui um dos melhores comentários sobre o pensador francês. Em Reclaiming constitui um dos me a uma discussão da crítica de Derrida a Husserl, Norris se desculpa por uma "exposição sumária e tortuosa". ${ }^{40}$ A observação é desculpa por uma "exposição sumária e toris uma habilidade admirável para sintetizar, de forma facilmente compreensivel, os entrelaçamentos complexos que pautam a maioria dos debates teóricos abstratos. O Marxismo althusseriano, a mecânica quântica, a epistemologia kantiana, Les mots et les choses de Foucault - o leitor encontrará resumos lúcidos e criticamente astutos de todas essas idéias, e muito mais, nas páginas dos sete livros.

Há momentos, contudo, em que a máquina teórica acelera além da medida. Assim, ao passo que a oposição de Foucault a uma teoria de poder marxista baseada em classes é bem conhecida, não é estritamente verdadeiro que sua versão do poder-saber "não seja mais uma questão [...] de algum interesse de classe específico ou máquina de estado que se mantém através do exercício de um desejo de poder soberano e jurídico". ${ }^{41}$ Discipline and punish - um fato pouco apreciado - lida com tipos de poder, obviamente privilegiando o poder disciplinar, microfísico, mas encontrando espaço para reconhecer o poder da burguesia. ${ }^{42}$ Além do mais e, especificamente nessa questão do pósmodernismo - de fato um ataque - não estou certo de que Foucault alguma vez tenha tratado a história como "um campo de forças de estratégias retóricas e interpretativas rivais". ${ }^{43}$ Seu trabalho delineia um quadro mais determinista no qual, em decorrência do seu entendimento apriorístico da produção do conhecimento humano, haveria apenas uma estratégia ocupando o campo a qualquer momento. Numa determinada configuração epistemológica, apenas certos savoirs eram possíveis. É por isso que a junção "Foucault-Lyotard" em Uncritical theory não é bem acurada (Norris escreve que trata as controvérsias, como aquelas em torno da Guerra do Golfo, "da forma Foucault-Lyotard como muitos discursos incomensuráveis"). ${ }^{44}$ É também por isso que há uma

\section{NORRIS, 1996: 55.}

41. NORRIS, 1991:51.

42. Foucauit M. Discipline and punish: the birth of the prison. Ironsl. Alan Sheridon. Karmondsworth, London: Penguin, 1977; reproduced 1986. p. 222

43. NORRIS, 1991: 138

44. NORRIS, 1992:11 
certa ironia no argumento de Norris, em Spinoza, de que a Nova História, a qual, ele afirma corretamente, segue Foucault de perto, se opõe a uma categorização discursiva a priori. ${ }^{45}$

Há, também, momentos em que a máquina teórica corre o risco de transformar-se num grande processador de informações, computando posições teóricas amplas de pensadores variados para defender os princípios mais gerais (verdade, crítica, etc.), percebidos como sob ameaça, mas no final produzindo resultados algébrico-crítico-teóricos. Esse é o problema da predileção de Norris por digressões em meio ao ensaio. Às vezes, eles enriquecem o debate; outras vezes, como é o caso da inserção de um trecho sobre Rorty num ensaio sobre Page duBois (em The truth about postmodernism), eles geram a impressão de que as posições críticas são bem elaboradas com antecedência. Parece-me que esse é o destino da teoria crítica. Quando Derrida desenvolve sua crítica ao trabalho de Foucault sobre a loucura, ele não está preocupado em falar sobre relatos históricos alternativos, ou sobre o insano nos países islâmicos. Seu objetivo é desconstruir o texto de Foucault, o que faz com perspicácia, um rigor surpreendente e muito brilhantismo estilístico. Sintetizado por Said, Spivak, Gordon, D'Amico, Bennington, Boyne, Frow, Sharman ou Norris, a crítica é reduzida a um conjunto de posições algébricas - a máquina teórica ou de paráfrase concluiu seu trabalho.

Nesse sentido, é evidente que, embora Norris tenha feito uma mudança institucional ao sair da literatura para um departamento de filosofia, seu público é composto de não-filósofos. Na verdade, ganha-se pouca experiência filosófica na leitura de Norris. Sua preocupação é apresentar um material (geralmente antigo) para aqueles não familiarizados com os debates. De forma análoga, para uma pessoa tão versada em Derrida como Norris, há, surpreendentemente, uma certa tagarelice em torno de, por exemplo, "questões concernentes ao mundo real factual, moral ou político", como se houvesse outras questões que não pertencessem ao "mundo" tout court. ${ }^{46}$ Além do mais, o que se quer dizer com o enigmático "a vida em Cardiff (onde eu leciono nos últimos quinze anos) tem a vantagem notável de que o mundo real ainda existe dentro de uma distância próxima para aqueles não totalmente mistificados pela conversa da realidade como um constructo textual"? ${ }^{47}$

45. NORRIS, 1991: 170

46. NORRIS, 1993:188

47. NORRIS, $1994: 6$.

\section{Teorias alternativas}

Um dos capítulos de Uncritical theory intitula-se "Alternative resources: against postmodernism". Através de sua crítica ao pós-modernismo e formas semelhantes de relativismo cultural, Norris oferece alternativas. De fato, uma de suas críticas mais ferozes está reservada para aqueles, sobretudo os teóricos da literatura, que permaneceram ignorando os desenvolvimentos principalmente na filosofia analítica e lingüística - que lançam dúvidas sobre os seus próprios paradigmas. ${ }^{48}$ Referindo-se ao uso excessivamente fervoroso da lingüística saussureana, que, para ele, foi ampliada de uma forma que teria causado perplexidade ao próprio Saussure, Norris argumenta que um dos pilares principais da confusão ético-epistemológica do pós-modernismo é "o modelo de compreensão lingüística redutor e excessivamente generalizado". ${ }^{49} \mathrm{O}$ problema com a idéia e um sistema lingüístico arbitrário ou convencional é que ele recrudesce numa posição relativista restrita. Assim, vigorosamente, Norris afirma sua posição: "se nós redefinirmos o 'verdadeiro' como 'verdadeiro relativamente a $L$ ' (onde $\mathrm{L}$ denota alguma língua, paradigma ou esquema consensual, uma 'comunidade interpretativa' ou o que for), então não há meios de mensurar $o$ assentimento comunitário". ${ }^{50}$ Em vários momentos, Norris invoca o modelo alternativo de linguagem desenvolvido por Gottlob Frege, Saul Kripke, Hilary Putnam e, posteriormente, Donald Davidson. É aí que se é grato à máquina teórica. Tomo a liberdade de citar Norris longamente numa bela condensação sintética das questões em What's wrong with postmodernism (embora eles recebam um tratamento muito mais completo no capítulo intitulado "Language, truth and historical understanding", em Spinoza):

De Frege, pode-se tomar o argumento de que o "sentido determina a referência" até determinado limite; que, embora aquilo a que as palavras se referem seja em parte estabelecido pelo seu papel nas várias sentenças, nos jogos de linguagem ou nos sistemas de significação, todavia é o aspecto referencial da linguagem que determina as condições de verdade, e assim serve de caso paradigmático para toda a compreensão lingüística. Tal posição encontra amparo na obra de filósofos contemporâneos como
48. NORRIS, 1992: 27-28.

49. NORRIS, 1994: 54

50. NORRIS, 1996: 172. 
Hilary Putnam e Donald Davidson. O que eles fornecem — concisamente - é um argumento contra a doutrina relativa de que toda língua codifica seu próprio conjunto distintivo de critérios referenciais ou semânticos, que os valores de verdade apenas podem ser determinados em termos de alguma língua específica (ou "esquema conceitual"); assim, cada ato de tradução entre línguas diferentes, discursos ou esquemas será sempre subdeterminado com relação às várias formas possíveis de construção de seu recorte conceptual ou semântico. Davidson emerge com uma objeção vigorosa a esse tipo de raciocínio, uma vertente que reúne pensadores, díspares em outros contextos, como W. V. Quine (sobre a relatividade ontológica), B. L. Whorf (sobre a etnolingüística) e Thomas Kuhn (sobre o caráter radicalmente "incomensurável" dos diferentes paradigmas científicos). Em cada caso, Davidson argumenta, eles criaram problemas desnecessários por via da suposição de que as questões de verdade apenas emergem no contexto dessa ou daquela língua específica. De fato, faz mais sentido começar pela premissa oposta, ou seja, que a pré-condição para sabermos qualquer língua - para a nossa habilidade de produzir, reconhecer ou interpretar sentenças na nossa própria língua ou em qualquer outra - $\varepsilon$ a atribuição a ela de certas propriedades básicas (valores de verdade, estruturas predicativas, expressões referentes, etc.), na ausência das quais a compreensão simplesmente não pode se iniciar. E esse argumento se aplica àquelas modalidades de pensamento pósestruturalistas ou pós-modernistas que, analogamente, incorrem em erros (como o considera Davidson) pela relativização da verdade e da referência à suposta multiplicidade de línguas, culturas ou "esquemas conceituais". Seu erro é simplesmente não perceber que a verdade é um tipo de primitivo lógico, um ponto de partida para qualquer tentativa genuína de compreender o que é inerente aos atos de tradução, bem-sucedidos ou não. ${ }^{.1}$

Norris está, aqui, tocando no "princípio da caridade" de Davidson, um princípio, como ele diz em Spinoza, ancorado em três pressupostos: "que as línguas fazem sentido, que suas formas de fazer sentido não podem diferir radicalmente de uma cultura para outra e, conseqüentemente, que os princípios

51. NORRIS, 1990: 186-187. generalizados de inferência que funcionam para uma língua também funcionarão - pelo menos até certo ponto - para a língua para a qual traduzimos". ${ }^{52}$ Sigo Norris na citação de Davidson:

Uma vez que a caridade não é uma opção, mas uma condição para se ter uma teoria operacionalizável, não faz sentido sugerir que incorreremos em vasto erro ao endossá-la. Até que tenhamos estabelecido com êxito uma correlação sistemática entre sentenças consideradas verdadeiras e sentenças consideradas verdadeiras, não há erros a cometer. A caridade é imposta a nós; gostemos dela ou não, se desejarmos compreender os outros, devemos considerá-los corretos na maioria dos assuntos. Se pudermos produzir uma teoria que concilie a caridade com as condições formais de uma teoria, teremos feito tudo que é possível para assegurar a comunicação. Nada mais é possível e nada mais é necessário. ${ }^{53}$

Uma outra fonte crucial de alternativas é o trabalho de desconstrução de Paul de Man e Jacques Derrida. A partir da crítica de Paul de Man a Fish, Norris arregimenta a insistência em não se reduzir tudo à retórica ou ao poder persuasivo, para que não se tornem obsoletos os valores epistemológicos de verdade, crítica e razão. De Man mantém, assim, a importância do trivium clássico (a lógica, a gramática e a retórica), soltando muito mais as rédeas do papel da retórica do que os tradicionalistas, mas argumentando a favor da importância ético-epistemológica de se respeitar os três elementos, na realidade, até certo ponto, uma impossibilidade lógica. ${ }^{54}$

Por outro lado, constitui um fato estranho no cenário acadêmico contemporâneo das Ciências Humanas - um fato não dissociado da máquina teórica e da preferência pela sinopse, o leitor, o manual, a "Introdução" - que, todas as vezes que Derrida é invocado por Norris, não é apenas para recrutar seu trabalho para o serviço de uma crítica do pós-modernismo; é, ao mesmo tempo, para rechaçar ataques de que o próprio Derrida é um pós-modernista, relativista ou anti-realista. Como Norris não se cansa de falar, é apenas necessário ler os ensaios de Derrida com uma quantidade módica de inteligência para perceber que seu trabalho não pode ser classificado através das inadequações conceituais de muitos outros pensadores. Sob a ótica de Norris, Derrida talvez

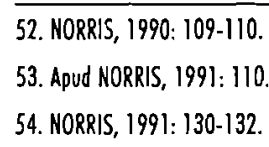


seja o único pensador rigoroso, coerente e desafiador que se enquadra na esfera de ação da teoria crítica. Norris não deseja ser sempre derrideano nas suas análises, mas Derrida nunca está distante do cenário.

Nos seus dois últimos livros, Reclaiming truth e New idols of the cave, Norris coloca, mais que nunca, Derrida em primeiro plano. Revisita dois dos principais ensaios de Derrida em Margins of philosophy, "The supplement of Copula: philosophy before linguistics" e "White mythology: metaphor in the text of philosophy" (na realidade, Norris os revisita duas vezes; novamente, a repetição prejudica a arquitetura geral dos livros), com o objetivo de demonstrar como, em cada um, Derrida contrapõe-se ao argumento, para Norris talvez $o$ artigo de fé para toda uma geração de pós-modernistas, de que a linguagem precede ao pensamento. "The supplement of Copula" trabalha com o argumento de Benveniste de que Aristóteles, um dos fundadores da Filosofia, não estava cônscio do fato de que as necessidades supostamente absolutas do pensamento "eram em si o produto de um conjunto meramente contingente, 'empírico', de restrições léxico-gramaticais pertinentes à língua grega antiga". 55 Em outras palavras, o pensamento depende da língua e, mais precisamente, de uma língua específica e não universal. Contudo, como demonstra Derrida, o próprio argumento de Benveniste faz transparecer exatamente o fenômeno reverso, pois ele recorre a "várias distinções estritamente categóricas" (como entre pensamento e linguagem, consciente e inconsciente, o conceitual e o empírico, 'a distinção de predicados' e a 'distinção de expressões') sem as quais ele não poderia ter desenvolvido nenhuma proposição dentro desse tópico"..$^{56}$ Uma vez colocados, os argumentos de Derrida possuem esta auto-evidência cegante que nos leva a pensar como foi possível ter se enraizado a posição contrária. Todavia, por outro lado, a persistência do caso contrário lembra-nos da força do hábito que se incorpora a certos preconceitos do pensamento e o conseqüente poder de vigilância que resulta do trabalho de Derrida.

O diagnóstico de Norris do status quo da teoria crítica invariavelmente atinge o alvo. São penetrantes seus comentários sobre a conversa difusa, "ritual", sobre a alteridade e o "outro", um discurso estruturado para opor-se à tendência etnocêntrica homogeneizadora da tradição ocidental e "cujo mero recitar é sempre considerado prova suficiente de que nós finalmente emergimos daquele velho e perverso discurso da razão opressiva monológica", ${ }^{57}$ ainda que, ao fazê-

55. NORRIS, 1997: 81-82

56. NORRIS, 1997: 84

57. NORRIS, 1994: 37 los, Norris pareça, aos olhos de muitos (sobretudo dos teóricos da literatura), um espectro no banquete. Para Norris, esse discurso "autocongratulatório" constitui um álibi para a consciência daqueles da esquerda cultural "que perderam todo o sentido de objetivo moral e político" ${ }^{58}$ Norris encontra a oposição a esse discurso num lugar inesperado, a saber, Julia Kristeva e seus dois livros Strangers to ourselves e Nations without nationalism. Muitos dos temas são conhecidos para aqueles familiarizados com o ensaio principal de Derrida sobre Levinas, "Violence and metaphysics: an essay on the thought of Emmanuel Levinas". Mas o capítulo de Norris sobre o assunto traz um discurso novo e diferente para o cenário, um fato do qual se suspeita e de que ele tem consciência, considerando-se sua escolha de citações. Kristeva, como Derrida, vê a necessidade de reconhecer o outro como um alter ego, "cuja existência não poderia exercer direito sobre a consciência moral de um indivíduo, se pensado enquanto existente num domínio de outridade absoluta e intransigente". Essencial é o autoconhecimento que descobre a alteridade dentro do eu, que nos torna todos "estranhos a nós mesmos". ${ }^{59}$ Argumentando contra o ceticismo - eu acrescentaria, o medo - daqueles que se esquivam em aventurar conexões entre o ser e o significado de ocidental e subalterno, ou que, pior ainda, poderiam ver no outro apenas a triste imagem especular de um poder-saber ocidental demiúrgico, Kristeva tem uma visão alternativa que é de Montaigne, mas é manifestamente transformada em sua:

O indivíduo deve, de fato, primeiro, ser um firme conhecedor de si próprio, conhecedor de seus males e de suas glórias, ser capaz de discorrer sobre eles de modo direto - sem banalidades ou pathos. Dessa maneira, o eu que foi assim criado, e não por determinado país, religião, tribunal ou política, se tornará o porto de partida para esse outro Renascimento que, para além das nações que estão se formando, estabelece comparações, relativiza, universaliza. Um novo cosmopolitismo está nascendo, não mais fundado na unidade das criaturas pertencentes a Deus, como concebeu Dante, mas na universalidade de um eu que é frágil, informal e, contudo, virtuoso e seguro. $O$ indivíduo de Montaigne, que nunca cessa de viajar no seu eu, já é um convite para se explorar o mundo e outros com a mesma bondade inflexível. .0 $^{60}$

\section{NORRIS, 1994: 38}

59. NORRIS, 1994: 81 .

60. NORRIS, 1994:89.
REVISTA DE ESTUDOS DE LITERATURA
Belo Horizonte, v. 5, p. $39-68$, out. 97 
Os temas da exploração e da bondade, tão belamente tratados, oferecem abrigo temporário da tempestade daquela "outra-língua".

Um outro esteio crucial para a visão alternativa de Norris é fornecido pelo trabalho recente na filosofia da ciência. Já à época de What's wrong with postmodernism, ele se valia da defesa feita por Roy Bhaskar da posição realista na filosofia da ciência, cuja articulação mais famosa se encontra em Scientific reason and human emancipation; interessante é que ele associa essa obra ao trabalho de Paul de Man. Tal conexão é bem astuta e a formulação de uma área compartilhada revela uma mescla admirável de matizes e rigor:

Cada um deles está comprometido com uma vigorosa versão dos seguintes fatos inter-relacionados: (1) que a verdade não é apenas o que fazemos dela de acordo com os consensos e as crenças prevalentes; (2) que essas crenças podem encontrar obstáculos reais, sob a forma de evidência empírica em contrário, incoerências teóricas, aporias textuais ou outros obstáculos semelhantes à compreensão; (3) que, quando problemas desse tipo ocorrem, é devido a um determinado erro de compreensão que pode, então, tornar-se o objeto de outras indagações críticas; e (4) que tais erros tipicamente emergem através da presença de motivos ideológicos ou interesses que permanecem obscuros - necessariamente - para aqueles que identificam a verdade tout court com o que é, no momento, "bom no tocante à crença". 61

Embora, desde o primeiro livro analisado, Norris tenha se proposto a olhar para além do paradigma pós-estruturalista, um fato evidenciado pela presença de Bhaskar, Putnam, Davidson, Frege, etc., as duas últimas coleções de ensaios assinalam um desvio acentuado no eixo do pensamento de Norris, um afastamento da teoria crítica para a filosofia pós-analítica e para a filosofia da ciência causal-realista. A última página de New idols of the cave sinaliza a filosofia da ciência de forma inequívoca: "Argumentei que a abordagem causalrealista é a única que traz a promessa de resolver as questões e, mais diretamente, de explicar como a ciência atingiu um grau tão alto de êxito explicativo ao lidar com o mundo físico". ${ }^{62}$ Como conseqüência, Norris ensaia um número de chavões argumentativos que emanam dessas tradições. Com relação à versão

61. NORRIS, 1990: 111-112.

62. NDRRIS, 1997: 243. vigorosa da tese da incomensurabilidade (de Kuhn), ele observa que nós não estaríamos em condições de reivindicar o caráter incomensurável de dois paradigmas diferentes se não fôssemos capazes precisamente de reconhecer as diferenças, admitindo, dessa forma, admitindo a possibilidade de pelo menos um "fundamento mínimo de comparação". Analogamente, nosso próprio conhecimento do crescimento do conhecimento, digamos, dos atomistas antigos à física atômica pós-Dalton é o que torna possível pensarmos em termos de uma certa linha de declínio, em lugar da imagem radicalmente descontínua sugerida pelos congêneres de Kuhn e Foucault.

A teoria causal-realista postula que as explicações científicas devem sua eficácia sobretudo às propriedades das coisas em si - suas estruturas, efeitos, "poderes eficazes transfactualmente" (a expressão é de Bhaskar) — em vez das várias proposições ou lógicas de indagação que parecem explicá-los. ${ }^{63}$ Norris argumenta, de forma persuasiva, que o renascer das ontologias realistas, este retorno, de certa forma, a Aristóteles, encontra respaldo em "White Mythology", de Derrida, onde já havia, contrariamente à disseminada leitura distorcida do ensaio, um reconhecimento "da existência de um mundo real, de um domínio independente da mente, cujo conhecimento é, contudo, alcançável". ${ }^{64}$

\section{Relatividade versus relativismo}

Concluo esta análise do trabalho de Norris sobre o pós-modernismo na década de noventa no ponto onde Norris escolhe terminar seu último livro, ou seja, com a ciência e a teoria causal-realista; mais especificamente, uma vez que a questão do relativismo aparece do princípio ao fim, concluo com a relação entre relativismo e relatividade. Norris crê que o trabalho teórico recente na ciência foi usado por muitos das Ciências Humanas para adicionar grãos ao moinho relativista. Assim, por exemplo, se a luz parece viajar tanto em ondas quanto em partículas ao mesmo tempo, qualquer pretensão a um conhecimento objetivo, determinado e decisível do mundo torna-se impossível. E há o gato de Schrödinger, supostamente existindo num estado superposto ambíguo (morto e vivo/nem morto nem vivo). ${ }^{65}$ Norris contrapõe-se a essas discussões retornando à teoria especial da relatividade. Ele argumenta que, uma vez que a teoria deve

63. NORRIS, 1996: 165.

64. NORRIS, 1997: 88.

65. Vide NORRIS, 1997: 215-216, sobre suo crítico oo entendimento errôneo do pardodoxo de Schroadinger. 
considerar a velocidade da luz como um absoluto ou medida de ponto-limite, ela não elimina uma estrutura comum através da qual se co-ordenam "campos de percepção de conformidade com as leis, inteligíveis para os humanos, de localização espaço-temporal e de sequiência causal". $O$ argumento de Norris é que, uma vez que as velocidades terrestres são geralmente modestas se comparadas à velocidade da luz, para todos os efeitos, nossas concepções normais (de Galileu) de espaço, tempo e movimento continuam válidas.

Há duas conclusões a serem tiradas. Primeiramente, que a teoria da relatividade não pode ser usada para se sancionar um relativismo éticoepistemológico do tipo "vale tudo". Em segundo lugar (e esta é uma intravisão importante que Norris enfatiza mais ao final do livro), há uma falha no argumento anti-realista ao "ajustar as contas com a diferença" - o abismo conceitual entre as ordens de conhecimento e indagação científica quânticas e macrofísicas. ${ }^{66}$ Ambas as conclusões nos lembram que a ética não é encontrada apenas na passagem para além da epistemologia - em direção, por exemplo, à política e à sociedade, ou à Guerra do Golfo. A epistemologia, também, impõe uma ética, uma responsabilidade com relação aos textos, pensadores e contextos, ainda que essa ética e essa responsabilidade não possam ser abstraídas e muito menos seccionadas do tecido do próprio pós-modernismo.

Tradução: Else Ribeiro Pires Vieira.

\section{ABSTRACT:}

This essay offers a critical exegesis of the seven books completed by the 1990s by the British critical theorist Christopher Norris on the subject of postmodernism, it being understood that Norris' subject-matter is postmodernist theory rather than postmodernist cultural artefacts or processes, in which he shows scant interest. In this trajectory, the threads of several questions are interwoven: what is
Norris' understanding of postmodernism? What are his objections to postmodernist theory? What are the grounds of his disagreement with Baudrillard in relation to the Gulf War? How is his note of hopelessness in relation to postmodernism explained? What is the impact of Margaret Thatcher's rightist politics upon his pessimistic reflections about postmodernist intellectuals in the early 90s? Mainly, the essay traces Norris' repeated criticism of the overextension of Saussurean linguistics, for him the root of much ill-thought out 'cultural relativism', and his lengthy commentary on Michel Foucault's shifting engagement with Kant. This encounter, Norris believes, illustrates in exemplary fashion the postmodernist turning away from the Enlightenment values of truth, critique and universal reason, the corollary of which, for Norris, is the severing of any principled link between intellectual work and the ethicopolitical. The essay also offers a number of criticisms of Norris (not least his practice of processing diverse positions in an unforgiving, abstracting theory machine) while highlighting the many alternatives to postmodernist theory which he explores (postanalytical philosophies of meaning, philosophy of science, causal realism, Derridean and de Manian deconstruction). The essay closes by establishing a distinction between relativity and relativism while highlighting that epistemology also entails an ethics and a responsibility - towards texts, thinkers and contexts - not Key-words: detachable from the fabric of postmodernism itself.

Postmodernist theory, Cultural malaise, Critical theory, Enlightenment, Ethics, Relativity, Relativism. 


\section{O MUNDO DO PODER E 0 PODER DA PALAVRA: UMA LEITURA DA FICÇÃO DE DON DELILLO}

Tom Burns

$U F M G$

\section{REFERERMCIAS BIBLIOGRÁFICAS}

FOUCAULT, M. Discipline and punish: the birth of the prison. Transl. Alan Sheridan. Hormondswarth, Londan: Penguin, 1977;

Foucault, Michel. L'Usoge des plaisis. Vol. 2. Histoire de 10 sexualitit. Paris: Editions Gollimord, 1984.

NORRIS, Christopher. Whot's wrong with postmodernism: criticol theory and the ends of philosophy. New York: Hovester Wheatsheaf,

NORRIS, Christopher. Spinozo and the origins of modern critical theory. Oxford: Bosil Blockwell, 1991

NORRLS, Christopher. Uncritical theory: postmodemism, intellectuols ond the Gulf Wor. London: Lowrence and Wishart, 1992.

NORRIS, Christopher. The Truth about postmodemism. Oxford: Basil Blackwell, 1993.

NORRS, Christopher. Irvth ond the ethics of crificism. Manchester: Monchester University Press, 1994

Manchester: Manchester University Press, 1997.

Adam. A ruse of reason: constitutionolist powers in the work of Michel Fouccult. Nottinghom: The University of

Nottinghom, 1985. (unpublished PhD thesis).

RESUMO

Este trabalho analisa alguns textos do romancista contemporâneo Don DeLillo, cuja obra Paul Auster diz ser fundamental para compreender a sociedade norte-americana neste fim de século. Nele pretende-se assinalar a natureza dos temas de sua obra e a relevância dos mesmos para um mundo globalizado, destacando-se os tópicos sobre o poder militar, o terrorismo e o poder do capital, tratando, em especial, a hegemonia das linguagens do poder e a resistência a elas. PALAVRAS-CHAVES:

fiç̧ão, poder, terrorismo, linguagems.

As primeiras obras de Don DeLillo foram publicadas no início da década de setenta, mas ganharam espaço no mundo acadêmico apenas nos anos oitenta. Atualmente, DeLillo vem se impondo a cada dia como o romancista norte-americano mais afinado com a história do seu tempo, uma primazia até então reservada a Thomas Pynchon. DeLillo tem constantemente reafirmado que o poder no mundo contemporâneo é invisível e mutável; seus escritos têm repetidamente apontado as conexões entre linguagem e poder, bem como a conflitante interação existente entre esses dois elementos. 